\title{
Un silencio elocuente o la paradoja del final de Marcos. "Y no dijeron nada a nadie porque tenían miedo" (MC 16, 8b) (II)
}

\section{Xavier Alegre,}

Facultad de Teología de Cataluña, Barcelona, Centro de Reflexión Teológica, San Salvador.

\subsection{El silenclo de las mujeres $(15,86)$ n la problemática del seguimiento del concificado}

El segundo recoque redaccional imporlante que Mc realizó en la trudición de la lumba vacia. lo encontramos en cl v. Rh'. Este reinquc no hice olra cosa. sino recoger una scrie de rasgos de su evangelio que, a modo de pisias de lcclura, han ido acompariando el relalo de la vida y de los milagros de Jesús de Nazarcl, así como la reucción que esta vida provoco, precisanenie, en sus seguidores, Tamiliares y umigos.

Mc concluye la tradición de la tumba vacia - iy todo el cvangelio! - con la observación, una vez ha mencionado el encargo de hablar, que el ángel ha dado a las mujeres: "Y no dijeron nada a nadie, porque tenian miedo".

¿A qué apunta estB observación tan sorprendente, que subraya que las mujeres no cumplieron la orden que Dios les habia dado, por medio de su mensajero? ¿Quicre acabar el evangelio con un modelo de desobedicncia? Obviamente. ćsti no puede ser la razón.

I. La mayorla de los especialistas considera hoy el $v$. Bb como redaccional (cfr. por cjemplo. Gnilka, op. cit., p. 395 y los autores citedos en la n. 660; K. Kenclge. Markusevangeliun, Würzburg, 1994, p. 161). Schmithals, Markus II, pp. 7145 picnsa, en cambio, que es de la tradición y que no se referia en ésla al v. 7. por lo que su interpolación resulta torpc. 


\subsection{Las interpretaciones de Mc 16, 8b}

El silencio final de las mujeres ha ocasionado muchos qucbraderos de cabeza a los especialistas. E. E. Bode. que dedicó su lesis docloral a estudiar los relatos de las visitas de las mujeres a la lumbu de Jesús, nos proporciona las cualro líneas fundamentales de explicación que hasla enlonces habian intentado los excgetas. $Y$ añade una explicación propia:.

Las cuatro propuestas fundnmentales sobre este silencio serian las siguientes:

a) quiere explicar por qué la "Icyenda"' de la tumba vacla permaneció tanto liempo sin que fuera conocida por las comunidades;

b) formaria parte de un molivo. propio de Mc, quc se ha denominado el "secreto mesiánico":

c) es sólo provisional (no callaron sicmpre) y condicionado (se referiria, por ejemplo, sólo al miedo de no ser creidas);

d) está motivado apologéticamente: quiere, por ejemplo. que los apóstoles. testigos oficiales de la resurrección, estén libres de cualquier conexión con la lumba vacia ( $i$ la fe pascual no surgió de ella!). o bien quicre poner de manifiesto la incomodidad de las primeras comunidades judeocristianas ante un acontecimiento testimoniado sólo por mujeres.

A estas explicaciones se puede añadir la que propone Bnde y la que dio, sobre lodo hacia los anos 70 , un grupo de aulores que lienen como rasgo común el hecho de subrayar el tono antiinstilucional que, según ellos, tiene el redactor de Mc:

e) el silencio quiere mostrar la respuesta humana paradójica a los mandamientos divinos:;

D) el silencio de las mujeres (Crassan, por ejemplo, nota, aludiendo a 3, 34s y 6, 3, que serian parientes de Jesús) se explica por una polémica intraeclesial del redactor: Mc quiere poner de manifieslo que la comunidad de Jerusalén, condu-

2. (fr. op. cis., pp. 30-44: en extes páginas se pueden encontrur Ins nomhres de los autores que abonan cady una de las distintas interpretaciones.

3. Según Grass. op. cil.. p. 20: "leyenda" se ha de entender aqui en el sentidn téenico de la "historia de las formas" y que mo implica, por si misma, ta no-historicidad de los hechos que relata; sohre la hisloricidad del descubrimiento de la tumba vacia, cfr. mi "noticia complementaria", citada en la nota 41 de la primera parte de mi articulo. Cfr. tambien G. Kittel, op. cit., p. $\mathbf{4 6 0}$ y los autores cilados por ella.

4. Según Bode. op. cir., p. 43, serla un elemento IJpieamente redaccional; cfr. también C. F. Evass, Resurrection and the New Testoment, Londres, 1970, que comenta: "16, B más bien enfatiza el acontecimiento comn divino, a Iravés de una reacción de desobediencia humana, y quizás evoca Marcos 10, 32". 
cida por los discípulos y Pedro, no ha aceptado nunca la llamada del resucitado, que le ha sido comunicada por la comunidad de $\mathbf{M c}^{\mathbf{S}}$.

Si prescindimos de la última explicación que, a mi juicio, interpreta de forma unilateral unos rasgos, sin duda sorprendentes, de Mc, quizás la solución que se ha de buscar no debe ser una solución de aut - aur (o una cosa o la olra), pues un texto literario puede ser mucho más rico de lo que aparece a primera vista. Pero, en cualquier caso, sí que hemos de intentar dilucidar cual es el motivo que domina sobre todos los demás y que el autor quiso subrayar primariamente. pues esto nos permitirá profundizar en su pensamiento. ¿Cuál es, pues, la interpretación de este texto lan sorprendente que pareee la más adecuada?

5. Asl, Crossan, op. cir., p. 149 (cfr., pp. 135-152). Pero cuando Mc eseribe su evangelio -iy este cexto es de la redacción! - ya hacla muchos arlos que la comunidad de Jerusalén no estaba dirigida por Pedro o por uno de los Doce. pues parece que muy pronto - en vida de Pedro- Santiago y los hermanos de Jesús tomaron la dirección de esla comunidad. El caracter antiinstitucional de Mc ha sido defendido muy vivamente - pero con argumentos poco convincentes- por T. E. Weeden. Mark - Traditions in Conflict. Philadelphia, 1968. Seguin este autor. el silencio de las mujeres quiere privar a los discipulos de sus credenciales apostólicas (cfr., p. 117); por eso Weeden imterpreta así 16. 8b: "Mareos anexó intencionadamente 16, 8b a 16. Ba como comentario final suyo, editorial, a su obra. El efecto, nahuralmente, es una sugessión inquietante, y para algunos ofensiva, de que los disclpulos nunca recibieron el mensaje del ángel. Asf, no encontraron nunca al Señor resucitado y, en consecuencia, nunca fueron comisionados con un rango apostólico después de su aposiasla" (op. cir., p. 50). Según este autor, los discipulos serfan los representantes de una concepción teológica deformada que veria a Jesús como el Theiós anér, el "varón divino", glorioso. Según W. esta concepción es la que Mc supone en sus adversarios teologicos (cfr. op. cir., pp. 101107). Notemos, con todo, que estn interpretación, si bien es unilateral y, a mi juicio, manipuladora de los datos que Me ofrece; sin embargo, puede ayudar a comprender mejor hasta qué punto resulta sorprendente la presentación de los discipulos, que realiza Mc, en su obra. Pero sólo se cae en la cuenta de ello cuando no leemos Me de manera superficial, desde una posición preconcebida. En una linea semejante a la de Weeden, irfa tambien la contraposición que según J. Leita (en El fonament irreligios de I'església, Barcelona, 1969, sobre todo a partir de la p. I 19) existirla entre la Iglesia que presenta Mi y la que ofrece Me. Por último quisiera sefhalar que segin J. Mateos, Los "Doce" y otros seguidores de Jesús en el evangelio de Marcos, Modrid, 1982, los textos de Mc ponen de manifiesto que existen dos grupos, en la comunidad de Mc: los que provienen de Istrel y son denominados "los disclpulos", de modo que constituyan luego un Irael mesí́nico ("los Doce"), y los que no proceden del Irrel institucional (judios o no). Con ello, Mc deja entrever las tensiones que sufría la Iglesia primitiva (cfr. sus conclusiones, en las pp. 247-258). Personalmente, creo que con esta interpretación no queda claro aquello que es, a mi parecer, la intención primordial de los textos, y por ello, no me parece uns interpretación adecuada. 
La interpretación opologética, que tiene, sin duda, sus razones de ser", no tiene suficientemente en cuenta que $\mathrm{Mc}$-a diferencia, por ejemplo, de Mt-. no realiza ningún otro retoque redaccional en la tradición de la tumba vacla que manifieste, ni de lejos, la más mínima preocupación apologética. No se ve, por tanto. por que molivo podrla querer concluir su obra, precisamente, con un rasgo de tipo apologético.

Las explicaciones a) y c), por otro lado, tampoco parecen suficientes. Sólo queda, entonces, la explicación que relaciona este silencio con el denominado "secreto mesiánico", que puede verse perfectamente en relación con la explicación e). ¿Encontraremos en esta línea la explicación del silencio de las mujeres? De hecho, la consideración de lo que, desde Wrede, se ha denominado el "secreto mesiánico", junto con el motivo teológico, lípico de Mc, de la incomprensión de la obra de Jesús, por parte de sus discípulos, de sus parientes y de sus seguidores en general, nos darh, pienso, la clave para poder comprender este final tan sorprendente de Mc.

\subsubsection{Ed "secreto meslánico"}

En el hecho de que en 16, 7, las mujeres reciban la orden de hablar, pero según 16,8 ballen, recordaria, según varios autores, el procedimiento inverso que hemos encontrado en varios textos de milagros. En ellos. Jesús daba la orden de que no se contara lo que él habra hecho, obteniendo, sin embargo, el efecto contrario: que aún lo contaran más'.

El silencio es, de hecho, un motivo propio de Mc, que aparece a menudo en su obra'. En estos lugares resulta también difícil de comprender y de explicar, a

6. Así lo constala Bode, op. cif., p. 42. Cfr. tambien H. von Campenhausen, Der Ablauf der Ostereneignisse und das leere Grab, Heidelberg, 1965, p. 39 (ffr. pp. 36ss), quien seriala que tate no era el motivo primario del silencio. Schmithals. Markus ПI, p. 714, en cambio, indica con razón que este no puede ser el motivo del silencio de las mujeres.

7. Asi, por ejemplo. Gnilka, op. cil., Il, p. 403. En cambio, H. Merklein, "Mk 16, 1-8 als Epilog des Markusevangeliums", en C. Focant (ed.). The Symopric Gospels. Leuven, 1993. p. 224, sostiene que no es así, pues las órdenes de silencio sólo son rotas en los milagros. El tampoco ve aqui una alusión al seguimiento de Jesús, en el camino de la cruz. El silencio de las mujeres apuntaría tan sólo a que el lector deje de aferrarse a la tumba vacla y se concentre solo en el kerigma (ibid., p. 233). Personalmente, pienso que Merkjein lo ve ast porque pierde de viste el conjunto de la dinámica del evangelio.

8. El primero que llamó la atención sobre este hecho y lo estudió sisteméticamente fue W. Wrede, en su obra Das Messiasgeheimnis in den Evangelien. Guttingen, 1901. Sobre el "secreto mesiánico" vale la pena consultar la obra de Minerte de Tillesse, anles mencionada, pues pone muy bien de manifieslo el aspecto redaccional del motivo (en el inicio de la obra, este autor da une historia de la interpretación de este tema). Cfr. también E. Schweizer, "Zur Frage des Messiesgeheimnis bei Markus", 
menudo. por qué se dan estas órdenes. Sorprende, por ejemplo, que en las tradiciones de exorcismos y de milagros, que recoge el evangelista -unas tradiciones que quieren revelar, sin duda, el pader de Jesús-, se encuentren con frecuencia, a menudo en textos considerados por muchos especialistas como obre de la redaeción, unas "ordenes de silencio", en las que Jesús probibe que se publique lo que él acaba de realizar (cfr. 1,$25 ; 1,34 ; 1,44 ; 5,43 ; 7,36 ;$ cfr. también 8, 26, donde el motivo está impliecito).

Estas órdenes, por otro lado, se ve, por el contexto, y en concreto, en los relatos de milagros, que no se pueden realizar ( $c f r .5,43$ con $5,38 \mathrm{~s}$ ) y son desobedecidas a menudo ( $f$ r. $1,44 s ; 7,36$ : "el [Jesús) les mandó que no se lo dijeran a nadje, pero cuanto más insisúa, más lo pregonaban"). En la misma línea, podemos ver el hecho de que Jesús, después de haber realizado algún milagro. quiera esconderse ( $c f r .1,35 ; 6,46 ; 8,9 ; 8,6 ; 9,30)$, sin que, sin embargo, logre conseguirlo (cfr. 7, 24).

Constatamos, en consecuencia, que tanto en las tradiciones -en principio independientes- de los milagros, como en las de los exorcismos -y en los sumarios o resúmenes redaccionales" - encontramos el motivo de las "órdenes de silencio". Este motivo, sin embargo, lo encontramos también en otro tipo de relatos. Por ejemplo, en 8, 30, inmediatamente después de que Pedro haya confesado que Jesús es el "Mesías"; o en 9, 9, después de que los disclpulos hayan sido testigos de la transfiguración de Jesús.

Podemos concluir, por tanto, que el motivo teológico, reflejado en las "órdenes de silencio", sale tan a menudo en Mc y en estratos tan distintos de la tradición, que liene que revelar un molivo importante para el redactor de $\mathbf{M c}^{10}$.

Zeitschriff fitr die Neutestamentliche Wissenschaft 56 (1965). pp. 1-8; U. Luz, "Das Geheimnismotiv und die markinische Christologie", Zeisschriff fllr die Neuresiamentliche Wissenschafi 56 (1965) pp. 9-30. Posteriormente, tambien Hoffmann, op. cit., p. 50 ha hecho notar que el silencio de Mc 16, Bb cae bajo "la reserva" (Vorbehalt) del "secreto mesiánico". En cambio, Pesch, Markus IL pp. 3647, defiende la lesis, a mi juicio sin convencer, de que el "secreto mesiánico" no tiene nada que ver con la labor redaccional de Mc y que, por tanto. no sirve para iluminar la teología del redaclor del evengelio, que el canon sitúa en segundo lugar. Pesch se fundamenta mucho en lo obra de H. Ruisănen, Das "Messiasgeheimnis" im Markusevangelium. Helsinki, 1976, el cual propone, sin embargo, una postura algo más matizada, pues según este autor sólo las ordenes de silencio a los demonios y a los discipulos forman parte del "secreto mesiánico" redaccional.

9. Por lo menos el motivo del "silencio" es redaccional: ofr. K. Kertelge. Die Wunder Jesu in Markusevangelium. Eine redakionsgeschichuliche Unrersuchung, Munchen, 1970. pp. 31ss.

10. Esta es la tesis, a mi juicio acertada, que defiende Minette de Tillesse. op. cis. pp. 219-221. 
La insistencia en el molivo nos indica, a la vez, hasta qué punto se debe enconurar aqui una idea leológica, que interesaba mucho a Mc. Por ello, debemos preguntamos por qué insiste el redactor tanto en este punto. $Y$ lambién por qué lo formula de este modo y qué es lo que él quiere que la comunidad cristiana, a la que dirige su obra, descubra en el texto.

Al analizar los textos parece. por un lado, que los distintos relatos de Mc tengen como meta manifestar quién es Jesús, revelar su poder. Pero, por otro lado, parece también que esta revelación deba permanecer "secreta". Esta es la razón que llevó a $M$. Dibelius a cualificar el evangelio de Mc como "el evangelio de las epifanias secrelas". ¿Por que, pues, ello es asi?

Una primera explicación del motivo del silencio nos la da el mismo Mc. Pues en 9, 9, nos indica el molivo y la duracion que debe tener la orden de silencio que da Jesús a sus discípulos, en este caso después de que hayan sido testigos de la transfiguración de Jesús. Allf leemos: "al bajar del monte, les ordenó que no contaran a nadie lo que habían visto hasta que el Hijo del hombre hubiera resucitado de entre los muertos". Según este texto, las "órdenes de silencio" están en relación con la cruz y resurrección de Jesús. Mc, por tanto, no se opone a la manifestación de la gloria de Jesús, sino que piensa que ésta no puede ser considerada aisladamente, sino que debe ser vista a la luz de la muerte y de la resurrección, que son como el marco teológico dentro del cual se deben siluar los milagros y los títulos mesiánicos de Jesús. Ś́lo en la perspectiva del crucificado se puede decir, con propiedad, que Jesús es el taumaturgo divino o el Mesías. Parece, por tanto, que las brdenes de silencio tienen una duración limitada: el "secreto mesiánico" llega sólo hasla el momento de la muerte y resurrección de Jesús.

\subsubsection{Un sllenclo elocuente}

Pero, ¿es Esta, entonces, la última palabra de Mc sobre el tema? Parece que no, si leemos con atención el texto que estamos considerando $(16,86)$. Pues pienso que lo que el silencio de las mujeres quiere mostrar es que la lógica teologica que se encuentra detrás del denominado "secreto mesiánico" sigue teniendo validez, incluso después de pascua. Desde esta perspectiva, el silencio de las mujeres resulta comprensible y se convierte en "elocuente".

En efecto, aquí nos encontramos con un procedimiento literario parecido al que hallábamos en los textos que han dado pie a la teorfa del "secreto mesiánico. Ś́lo que aqui, la diá́nica es de signo contrario. Si en distintos milagros Jesús manda

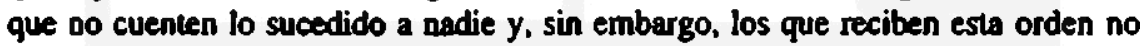
la obedecen, pues en vez de callar hablan..., aqul sucede lo contrario: las mujeres reciben la orden de hablar, pero no obedecen, sino que callan...".

11. Cfr. Gnilka, op. cir. П. pp. 403. También Kertelge, Markusevangefium, p. 163. ve representado aquif el motivo del silencio marcano. Según J. D. Kingsbury, The 
Por otro lado, en este contexto el miedo. que explica aparentemente este silencio desconcertante (v. 8b), deja de ser primariamente la reacción normal de los seres humanos ante una angelofanía. En principio, esta reacción religiosa debía ser el sentido inicial del miedo a nivel de la tradición de la tumba vacfa que Mc recibió. Y, de hecho, éste es el sentido que el miedo tiene en los vv. 6a y 8a, también en el nivel de la redacción de Mc'2 . Pero ya no es así en el v. 8b. El cambio de sentido del motivo teológico del miedo en el v. 8b se descubre en el hecho de que el miedo es presentado aquí de forma negativa, ya que justifica un silencio que está en contradicción con la orden explícita del ángel. Un silencio que resulta aún más negativo por el hecho de que el ángel no ha hecho otra cosa sino recordar una palabra y un encargo que Jesús de Nazaret había dado a sus discípulos, poco antes de su pasión (cfr. 14, 28).

Seria ingenuo por nuestra parte suponer que Me no cayó en la cuenta de que este silencio de las mujeres sorprendería a los oyentes o lectores de su evangelio. Pues contrasta con lo que parece que deberian esperar, de acuerdo con lo que Jesús había dicho a sus disclpulos en 9, 9 ("que no contaran a nadie lo que habían visto hasta que el Hijo del hombre hubiera resucitado de entre los muer(os"). Esto supuesto, si lo mantiene, más aún, si, como parece, es él el que crea este silencio aquí, después de la resurrección de Jesús, ello significa que Mc le quiere dar a este silencio un sentido especial e importante para él. Pues nos encontramos aqul con un motivo que ha sido como uno de los leit morivs de su obra. Pero a partir del texto de 9, 9, el lector podia haber sacado la impresión de que el silencio sólo tenía que guardarse - tenía validez - hasta que Jesús hubiera muerto y resucitado. Con ello se indicarla, simplemente, que sólo desde la perspectiva de la cruz, que desemboca en la resurreccion, se podían comprender las manifestaciones poderosas de Jesús (milagros, transfiguración, etc.). $Y$ que una vez se hubiera adquirido esta perspectiva, se podla hablar con tranquilidad de las manifestaciones de Jesús con poder.

Pero, por lo visto, no es así. Pues si después de la revelación de la resurrección de Jesús, por parte de un ángel, los motivos teológicos del silencio y de la incomprensión del mensaje de Jesús vuelven a aparecer -iy en un lugar clave y sorprendente de su evangelio!, ello significa que para Mc, lo que quiso comunicar a su comunidad con estos motivos sigue siendo válido también después de pascua.

Como veremos luego, al estudiar el silencio de las mujeres, Mc quiere que su comunidad caiga en la cuenta de la complejidad y de la dificultad que com-

Christology of Mark's Gospel, Philadelphia, 1983, p. 155, el motivo del secreto en Me sirve para mostrar cómo se pasa, a propósito de la persona de Jesús, del modo de pensar humano al modo divino de pensar.

12. Cfr. Pesch, Markus II, p. 535; Bode, op. cir., pp. 37-39. 
porta, por sí misma, la comprensión de la revelación cristiana. Dicha comprension no queda garantizada por el mero hecho de haber sido testigos de las obras gloriosas de Jesús o de haber recibido el mensaje divino de la resumección. En este sentido, podemos decir que el silencio de las mujeres le sirve a Mc. como veremos, para dejar bien claro lo que ha sido como la intuición teologica nuclear de toda su obra. Una intuición que guió la estructura que Mc quiso dar a su evangelio ( $c f r$ infra). Me refiero a una firme convicción de Mc que, por cierto, parece un buen disclpulo teológico de Pablo's: la convicción de que la cruz del resucitado es como el catalizador de todo el pensamiento cristiano. Consecuentemente, la sombra del crucificado ha de planear siempre sobre todo seguimiento de Jesús. Se trata para él de un seguimiento que ha de ser. por esencia, también después de pascua, un seguimiento en el camino de la cruz (cfr. B, 34ss). La insistencia en este aspecto se debe a que Mc parece estar preocupado por el hecho de que sus cristianos pueden comprender mal a Jesús, por el hecho de que no estén dispuestos a seguirle en el camino que, en un mundo injusto como el nuestro, lleve a la cruz.

En esta perspectiva se comprende bien, también, que, si la comunidad tenfa una cierta tendencia - como parece que podemos deducir de los acentos que Mc dio a su obra- a fijarse excesivamente en los aspectos gloriosos de Jesús, en detrimento de los aspecto que lo llevaron al conflieto con las autoridades de su tiempo - y a la cruz ${ }^{14}$-, que Mc no tuviera el más mínimo interés en concluir su evangelio con un relato detallado de las apariciones pascuales, que habrian podido fomentar aún más estas tendencias triunfalistas de sus cristianos.

Todo esto, sin embargo, quedará aún más claro si analizamos el papel que Mc hizo jugar a las mujeres y, en general, a los seguidores de Jesús.

\subsection{Papel de ln familia, de los discípulos y de los seguidores de Jerís}

Los textos que hablan de estos personajes llevan claramente, a la luz del contexto del evangelio, la impronta de la teología del redactor.

13. Según J. Marcus hay una relación entre la teologia de Pablo y la de Mc: efr. "Mark - Interpreter of Paul", New Testament Studies 46 (2000), Pp. 473-487; cfr. también el volumen primero de su comentario a Mc: Mark 1-8, New York, 2000, pp. 73-75: M. D. Goulder, "Those Outside (Mk. 4, 10-12)", Novum Tesiamentum (1991). pp. 289-302; J. R. Donahue, 'The Quest for the Community of Mark's Gospel", en The Four Gospels 1992. Fs. F. Neirynck (ed. F. van Segbroeck ef aL), Leuven. 1992. vol. 2. pp. 817-38; W. Schenk, "Sekundire Jesuanisienungen von primären Paulus-Aussagen bei Marlous", The Four Gospels 1992, pp. 877-904; J. R. Donahue, "Windows and Mirrors: The Setting of Mark's Gospel", Carholic Biblical Quarterly 57 (1995). pp. 1-26; H. Rajisànen, "Jesus and the Food Laws: Reflections on Mark 7. 15", en Jesus, Poul and torah: Collected Essays. Shefifield, 1992 [1982], pp. 127-148.

14. Cfr. X. Alegre - L. Tuñ, "Los milagros, ¿erítica a una religiosidad triunfalista?". Sal Terrae 62 (1974). pp. 443-449. También Kingsbury, op. cif., pp. 25-45, sostiene que 
En efecto. una comparación sinóptica de la manera cómo los evangelistas tratan la figura de estos personajes venerables, muchos de los cuales fueron las columnas de la fe de la comunidad ( $c f r$. Gal 2, 9), revela, por un lado, cómo Mc subraya, de manera sorprendente y consecuente, la incomprensión de la persona de Jesús, por parte de lodos ellos; mientras que, por el otro lado, los demás evangelistas. y sobre todo $L c$, se esfuerzan por suavizar o por cortegir -en la medida en que la fidelidad histórica, tal como se entendla en la época, lo permitía- los textos, en los cuales lodos ellos quedaban tan mal, en Mc.

\subsubsection{La incomprensión de la famillia}

Los primeros amigos de Jesús que en Mc quedan mal por no poder entender a Jesús, son los de su familia. Los textos en cuestión los encontramos en 3. 21 y en 3, 31-35. Mc recoge aquI, sin duda, tradiciones de la comunidad. Pero sitra estos lextos en un contexto tan negalivo - sobre todo si se tiene presente que sirve a Mc de inclusión una pericopa, que nos ofrece las interpretaciones malintencionadas de la figura de Jesús, por parte de los adversarios por excelencia

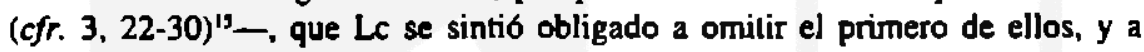
modificar el segundo texto, asi como umbién su contexto, pues pensaria que daban una imagen excesivamente negativa de la familia de Jesús. Y se siente obligado a modificarlos, porque se trata de una familia que, según nos recuerdan los Hechos de los Apóstoles. jugó un papel importante en la lglesia primitiva's.

Mc quiere poner un correctivo a una cristologfa que destaque los aspectos gloriosos de Jesús. Tolbern, en cambio, no cree que Mc quiera corregir una determinada cristología de su audiencia. por lo que llega a otra conclusión en su obra: "En base a nuestra interpretación literario-histórica, sugerimos que el evangelio de Marcos no lue escrito para responder a los problemas de una comunidad especifica, local, sino que más bien estaba pensado, como ocurría con las antiguas noveles eróticas, para un amplio público de lectores" (op. cir., p. 304).

15. El contexto es una creación claramente redaccional de Mc. Por otro lado, el procedimiento literario de "sándwich" es tĺpico del redactor (cfr. Minette de Tillesse, op. cit., p. 52, y los autores citados por él). El vocabulario del v. 20 manifjesta también el sello de la redacción de Mc: "Volvió a casa, y de nuevo se reunió tanto gente que no podian ni comer".

16. Cfr. Le 8, 19-21. La comparación con Me muestra que el v. 19 corresponde a Mc 3 , 31. En cuanto a Mc 3, 21, Lc to omite totalmente. $Y$ sinia Mc 3, 22-30 en otro contexto (cfr. II. 14-15.17-22; 12, 10). En cuanto a Lc 8, 19-21, podemos ver que está siluado después del sermón que empieza con la parábola del serabrador, que ha hablado de los que escuchan la palabra de Dios y la cumplen (cfr. Lc 8. 5). Este nuevo contexto, y las modificaciones redaccionales que realiza en el texto de Mc. hacen que la perícopa tenga ahora, en el tercer evangelio, un sentido nuevo $-y$ positivo en relación a la familia de Jesus - con respecto al texto que reproducla Me. Pues, al cambiar el contexto que teniamos en Mc. al suprimir la pregunta de Mc 3. 33b ("¿Quiénes son mi madre y mis hermanos?") y al quitar las palabras "estos son 
Lo primero que Mc nos indica sobre la familia de Jesús es muy negativo. Dice que consideraba que Jesús se habla vuelto loco:

Volvió [Jesús] a casa, y de nuevo se reunio tanta genie que no podian ni comer. Sus parientes, al enterarse, fueron para llevárselo, pues declan que estaba trastomado $(3,20-21)$.

Y si a continuación Mc añade que los maestros de la Ley, que habfan venido de Jerusalén, afirmaban que Jesús estaba endemoniado (cfr. 3, 22ss), ello implica que el evangelista tenía interés por nostrar que la familia de Jesús tenía un nivel de comprensión de la persona del Maestro que era parecido al que tentan los grandes enemigos de Jesús.

Por esto resulta tambien "escandaloso", en este contexto, que Mc nos vuelva a decir, a continuación, de la familia de Jesús:

Llegaron su madre y sus hermanos $y$, desde fuera, lo mandaron llamar. La gente estaba sentada a su alrededor, y le dijeron: " $O$ Oye! Tu madre, tus hermanos y hermanas están fuero y te buscan". Jesús les respondio: " ¿Quiénes son mi madre y mis hemnanos?". Y mirando entonces a los que estaban sentados a su alrededor, añadio: "Esios son mi madre y mis hermanos. El que cumple la voluntad de Dios, ese es mi hermano, mi hermana y mi madre" (Mc 3, 31-35; los subrayados son inios, pero se deducen del texto).

En el contexto adverso de Mc. que acabo de mencionar, parece, entonces, que la contraposición entre los que estaban sentados alrededor de Jesús y su familia, no solamente implica que ésta no entendía a Jesús ( $c f r .3,21$ ), sino que. además, tampoco hacía la voluntad de Dios ${ }^{17}$.

¿Por qué presenta Mc de modo tan crítico a la madre y a los hermanos de Jesús, unos personajes que, como sabemos por otros textos del Nuevo Testamento, eran vistos positivamente por las primeras comunidades cristianas?".

mi madre y mis hermanos" (Mc 3, 34), Lc suprime la contraposición que parecfa establecer entre la familia de Jesús -que no entiende a Jesús (cfr. Mc 3. 21) y quizás no cumple la voluntad de Dios ( $f r$. Mc 3, 33a) - y los que la cumplen. Como sabemos por los Hechos de los Apóstoles, Le está interesado en presentar positivamente a Maria (cfr. tambien le 1-2) y a los hermanos de Jesús ( $f$ r. Hch 1, 14).

17. En el contexto de $\mathrm{Mc}$, el v. 35 más que suavizar el contrasle entre los seguidores y los parientes de Jesús (asf lo interpreta, por ejemplo, Gnilke, op. cit., I, pp. 178s). subraya que la relación con Jesús viene dada por el eumplimiento de la voluntad de Dios que, en Me, viene sefialade por el seguimiento de Jesús, en el camino radical que lleva a la cruz (cfr. Pesch, Markus, I, p. 223).

18. Cfr. R. E. Brown; K. P. Donfried; J. A. Fitzmyer y J. Reumann, Marfa en el Nuevo Testamento, Salamanca, 1982. 
Creo que la respuesta no se encuentra, como han propuesto ajgunos, en la animadversión de Mc contra la Iglesia de Jerusalén', en la cual, sin duda. Sanliago y los otros hermanos de Jesús ocuparon un lugar relevante (cfr. Hech 15 y Gal 2). Mc estaría más bien impulsado por el deseo de llamar la atención de su comunidad, con ayuda del ejemplo "negativo" de unos personajes tan venerables como la madre y los hermanos de Jesús. sobre el peligro real que amenaza a su comunidad, si no está dispuesta a aceptar a Jesús de Nazaret, lal como se manifestó en realidad durante su vida pública. Y si no esta dispuesta también a seguirlo, en el camino que lleva a la cruz. Pues, si a unos personajes tan venerables les costó tanto, de entrada, comprender el camino concreto de Jesús, ¿cómo pueden pensar, sin más, que ellos sí han comprendido este camino tan altemativo de Jesús?

\subsubsection{Incomprensión de los discípulos}

Es, sobre todo, durante el relato de la pasión de Jesús cuando aparece más clara la contraposición entre la figura de Jesús (y la manera como va a la cruz) y la figura de los discipulos (y la manera como éstos procuran escapar a la cruz).

Mc subraya aqui -siguiendo, en parte, lo que ya enconlró en sus fuentesel fracaso de los discípulos. Pues es un discipulo, Judas Iscariote, uno de los Doce, el que traiciona a Jesús ( $c f r .14,10 ; 14,20$ s; cfr. también 3, 19). Y en el momento en el cual Jesús será tomado preso ( $f f r .14,43-52$ ), todos los discípulos lo dejarán solo y huirán (cfr. 14, 50; también 14, 5I s), de modo que al pie de la cruz sólo se encontrarán, según Mc. unas mujeres, que habían seguido a Jesús desde Galilea (cfr. 15, 40s). Incluso Pedro, el portavoz de los discípulos, que habla proclamado que estaba dispuesto a morir con Jesús (cfr. 14, 29-31), lo negará tres veces - la última, entre maldiciones y juramentos-, precisamente, en el mismo momento en que Jesús es sentenciado a muerte por el sanedrín y tiene que soportar las burlas de sus adversarios ( $f f r .14,66-72$ con 14, 55-65) ${ }^{20}$.

El triste papel que Pedro y los Doce desempeñan durante la pasión no tiene por qué sorprender a los lectores y oyentes de Mc. De hecho, ya en Betania, en casa de Simón el leproso. Mc los habla presentado" de modo que quedara bien patente su incomprensión de la acción de la mujer que derramó el perfume sobre

19. Cfr. supra n. 63 y Schenke, op. cir., pp. $49-52$, n. 71.

20. Le suavizará también estos rasgos negativos, tal como acostumbra hecer, en su obra (cfr. G. Schneider, Die Passion Jesu noch den drei albesten Evangelien, München, 1973, pp. 80-82).

21. Mc no indica de modo explícito que sean, precisamente. los discípulos los que protestan ante el despilfarro que supone el cosie del perfurne que emplea la mujer, que unge a Jesús (cfr. 14, 4.5). Pero por el contexto, parece obvio que debieron ser ellos. $Y$ asf lo interpretan Mt. en el texto paralelo ( $f f r .26,8), 0 \mathrm{Jn}$, en el equivalente ( $c f r$. 12, 4-6: pone la crítica en boca de Judas).

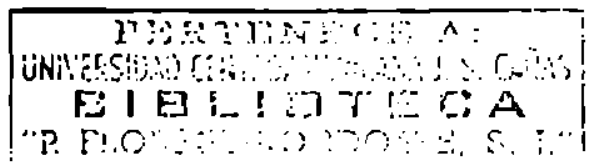


la cabeza de Jesús. Precisamente, estas criticas les reportarán un reproche claro, por parte del Maestro (cfr. 14, 6-9 par).

También en Getsemaní, mientras Jesús ora y se prepara para la pasión ( $\mathrm{ffr}$. 14,33ss), Pedro, Santiago y Juan, representantes conspicuos de los diselpulos. duermen (cfr. 14, 37.40.41: ¡lo subraya tres veces!, indicando as! el fracaso clamoroso de los discípulos), a pesar de que Jesús les habla pedido explícitamente que velaran con el $(e f r .14,34)$. Por eso, Jesús le dirá a Pedro: "Simón. ¿duermes? ¿No has podido velar ni siquiera una hora? Velen y oren para que puedan hacer frente a la tentación, que el espíritu está bien dispuesto, pero la came es débil" (14, 37b-38).

Este fracaso de los discípulos lo había explicitado ya el redactor del evangelio de Mc, desde el momento mismo en que Jesús empieza a hablar abiertamente de la pasión ( $c f r .8,32 a$ ). Pues despues de cada predicción de la pasión (cfr. B. 31; 9, 32-34; 10, 32-34) ${ }^{2}$, Mc sitúa siempre -y ello es fruto de su trabajo redaceional- una perícopa que manifiesta su incomprensión radical del misterio de la cruz (cfr. 8. 32s; 9, 32-34; 10, 35-41) ${ }^{n}$.

Este motivo de la incomprensión y del fracaso de los discípulos de Jesús le parece tan importante a Mc que lo pone también en otros textos de su evangelio. Un texto muy interesante, en este sentido, lo encontramos en el milagro de la tempestad calmada por Jesús (efr. 4, 35-41). Pues en un texto que es propio de

22. También aquí pone Mc tres anuncios de la pasión para indicar la importancia del tema; tres, en el mundo b́blico, indica siempre plenitud.

23. En este fragmento $(8,27$ - 10, 45), enmarcado por los dos relatos de curación de un ciego, que aparecen en Me (cfr. 8. 22-25 y 10, 46-52), aparece claramente la mano del redactor del evangelio (cfr. Best, op. cit., pp.15-146; también M. Horstmann, Studien zur markinischen Christologie. Mk 8, 27 - 9,13 als Zugang zum Christusbild des zweiren Evangeliums, Minster, 1969, que estudia una parte importante de este fragmento). Esta labor redaccional aparece tanto en la estructura, que subraya la incomprensión de la cruz. por parte de los discípulos, como en la insistencia con que se nos indica que el "camino" de Jesurs es el camino de la cruz. En este contexto, las curaciones de los ciegos adquieren un significado simbólico profundo para Mc. Pues con estos dos relatos. el redactor del evangelio nos quiere indicar dos cosas: 1) sólo si Jesús nos abe bien los ojos (no basta una acción superficial, que nos llevaria únicamente a una visión insuficiente, a ver "a los hombres como úrboles que caminan": cfr. 8, 24; este texto prepara ehora la visión insuficienle que tienen los hombres sobre Jesús, en 8. B. 28) podemos ver con clarided quién es Jesuis ( $f$ fr. B. 25; como Pedro que es capaz de confesar que Jesuis es el Meslas, en 8. 29, aunque esta confesión, en este momento del evangelio de Mc, se preste auin al malemendido y por esto va ecompanada de la "onden de silencio", en 8. 30). 2) No basta con que Jesús nos abra bien los ojos. Para poder seguir a Jesús, en el cemino de la cnuz, es necesario que el Moestro nos capacite para ello, como le ocumió a Bartimeo, a quien Jesús no sólo abrí́ los ojos. sino que lo capacito "para seguirto en el camino" de la cruz ( $f$ r. 10, 52; ffr. Besh, op. cir.. p. 146). 
la redacción de Mc 一rompe la estructura típica de los relatos de milagro ${ }^{34}$-. Jesús hace el siguiente reproche a sus discipulos, que acaban de ser testigos del milagro: “¿Por qué son tan cobardes? ¿Todavfa no tienen fe?” $(4,40)^{23}$.

Se trata, precisamente. de los discípulos de los cuales, poco antes, se ha indicado que no entienden el sentido de las parabolas. Jesús les habla dicho: ¿¿No entienden esta parábola? ¿Cómo van a comprender entonces todas las demás?" $(4,13 ;$ cfr. 4, 10 y lambien 7, 18). Un reproche tanto más doloroso cuanto que Me ha indicado en 4. 11 ss.14ss.34, que Jesús se lo explicaba todo a los discípulos.

Son los discípulos que responden de modo absurdo a las preguntas que Jesús les dirige (cfr. 5,$31 ; 6,37)$ y que fácilmente olvidan lo que han visto y ofdo, cuando Jesús ha realizado la primera multiplicación de los panes $(c f r .8,4)$. Son los discipulos que confunden a Jesús con un fantasma (cfr. 6, 49). Son los discipulos que no han entendido en absoluto las dos multiplicaciones de los panes y se han situado a un nivel de comprension. que recuerda la que es propia de las personas "de fuera", las que no tienen fe (cfr. 8, 17-21 con 4, 10-12). Son los discípulos que son incapaces de expulsar algunos demonios (cfr. 9, 18b.28-29) y que no permiten que los niños puedan ser llevados a Jesús (cfr. 10. 13s).

Si tenemos en cuenta todos estos textos, ya no nos sorprenderá que Pedro. como representante de los Doce, haga propuestas absurdas, cuando Jesús se les aparezea, transfigurado, en la montaña, pues "no sabla lo que decla" $(9,6)$. Como tampoco resulta sorprendente, entonees, que euando Jesús diga que "le es más fácil a un camello pasar por el ojo de una aguja, que a un rico entrar en el reino de Dios" (10.25), los discipulos pregunten, asustados: "entonces, ¿quién podrá salvarse?" $(10,26 \mathrm{~b})$.

Después del repaso de estos textos numerosos, que aparecen en tradiciones tan distintas, a lo largo del evangelio de Mc. creo que podemos sacar la conclusión de que la incomprensión de los discípulos es un motivo que ha sido incorporado a los relatos evangélicos, en lo fundamental, por la labor redaccional de $\mathrm{Mc}^{23}$. Representa, pues, un interts particular del evangelista.

¿Cuâl es, pues. este interés? ¿Qué nos quiere hacer ver Mc con este motivo de la incomprensión de los discípulos?

24. Cfr. Peseh, Markus I, pp. 268 y 274.

25. Tal como suele ocurrir, en sus respectivos evangelios, Mt y Le suavizarán este reproche de Jesús a los discípulos (cfr. Mt B, 26 y Le 8, 25).

26. Cfr. K. G. Reploh, Markus - Lehrer der Gemeinde. Eine redaktionsgeschichtliche Siudie zu den Jungerperikopen des Markusevangeliums, Stungart, 1969, pp. 75-88. Ya Wrede, op. cit., pp. 81-114, habla indicado que la incomprensión de los discipulos era un rasgo úpico de Mc. 
Una explicación posible $-y$ es la que han intentado algunos autores ${ }^{n}$ - es que Me escribio su obra para oponerse a la institución eclesial, representada por los discípulos. Si Mc, en efecto, hubiera respirado un espiritu antiinstitucional, entonces se comprenderia perfectamente su interes en hacer quedar mal a los diseípulos, que se convertirfan, asl, en los representantes de la jerarquía eclesial.

Pero personalmente - y es el parecer de la mayoría de los especialistas- no creo que sea ésta la explicación de los textos. pues en diversos lugares, Mc habla muy positivamente de los disclpulos ${ }^{2 x}$. $Y$ en 16,7 , un texio que acabamos de ver, nos indica, de formo explrita, que el resucitado vuelve a llamar a Pedro y a sus discípulos y les encarga que vayan a Galilea, pues alló lo "verán". Nada indica, pues, que lo palabra de Jesús tuviera que follar.

Esto supuesto. la interpretación de estos textos sobre la incomprensión de los discipulos tiene que ser más matizada. Creo que Me no quiere desautorizar a los discipulos, sin más (al fin y al cabo es a través de ellos como él y su comunidad han llegado a conocer las tradiciones de Jesús). Más bien pienso que quiere aprovechar el hecho de que la comunidad ve positivamente a Pedro y a los Doce para dar una lección a sus cristianos. Una lección que le parece importante, pero diffeil de aceptar. Es una lección que está en relación con lo que hemos visto antes, a propósito de orro motivo redaccional. Me refiero a las "ordenes de silencio". Es la lección de la cruz. Para Mc, sólo si se está dispuesto a seguir a Jesús, de modo radical, en el camino que lleva a la cruz, en un mundo injusto, se puede entender, de verdad, quién es Jesús.

Mc tiene, por lo visto, que "cargar las tintas" en este punto porque tiene la impresión $\rightarrow$ por lo que podemos deducir de los acentos que pone en su obra- de que su comunidad parece que no lo entiende así. A la comunidad le agrada más bien una imagen triunfalista de Jesús ${ }^{29}$. Al evangelista le debe parecer que ella piensa que ya está en el camino de Jesús y no cae en la cuenta de que algunas

27. Cfr. supro n. 5.

26. Jesús los llara personalmente ( $f f r, 1,16-20)$. los escoge para una tarea particular y para que estén con el (cfr. 3. 13-19). los envia a predicar con poder para expulsar a los demonios (cfr. 6.7-12) y subraya su éxito (efr. 7. 12 y 30). los hace paricipes de una instruceión privilegiada (efr. 4, 10ss.34; 7, 17ss; 3, 3ss). Por otro lado, Me nunea indice que Jesús acnie, si sus discípulos no estân presentes. Véase también. en la misma linea de interpretación que propongo, Achtemeier, op. cir., pp. 92.100: Gnilka. op. cif.. l. pp. 26-28; vease tambien la critico de V. Fusco a la tesis de Weeden, en Parola e Regno. La sezione delle parabole (Mc 4. 1.34) nella prospestiva murciana. Brescia, 1980. pp. 145.150 (la manera como Fusco interpreta el motivo de la incomprensión de los discípulos en Me difiere un poco de la que yo propongo: cfr. Parola. Pp. 135-144).

29. Este aspecto lo destaca Reploh, op. cir., pp. 87-231; cfr. tambien E. Schweizer, Das Evangelium nach Markus, Götingen. 'J968. pp. 220-224: Steichele. op. cis.. pp. 303s. En cambio Tolbert (cfr. supra n. 76) no lo ve asl. 
concepciones sobre Jesús, propias de una cristologia de tono triunfalista. merecen el reproche de ser un "Satanás", reproche que ya un hombre tan extraordinanio y querido por Jesús, como Pedro, mereció por no querer aceptar la "lógica" de la cruz (cfr. 8, 33).

Mc, por tanto, con los acentos que pone en su obra se propone sacudir una falsa autoseguridad, que parece afectar a su comunidad. Una comunidad que se crela, por lo visto, que ya disponía de la clave de lectura para comprender la vida de Jesús. cuando la interpretaba gloriosamente. Por eso. Mc toma la ligura de unas personas tan importantes y significativas para la comunidad cristiana, como son Pedro y los Doce (o la familia de Jesús, según he indicado antes). y simboliza en ellas lo que le pudía ocurrir a todos cristiano - por más bautizado que estuviera y fuera cuál luese el papel que desempeñara dentro de la comunidad-, si no toma conciencia de cuâl es la auténtica interpretación de la persona de Jesús. Una interpretación que pasa por la disposición sine qua non de todo seguimiento cristiano: estar dispuesto a seguir a Jesús, en el camino que Lleva a la $\mathrm{Cruz}^{30}$. Pues si los discípulos, testigos privilegiados y escogidos personalmente por Jesús, fracasaron, mucho más le puede ocurir esto a cualquier miembro de la comunidad cristiana.

\subsubsection{3. ¿Tampoco las mujeres comprendieron?}

A medida que lefamos el evangelio. Mc nos iba rompiendo todas nuestras posibles "seguridades" religiosas, preparando asi el que tomáramos conciencia de que, a lo mejor, no habíamos comprendido a Jesús todo lo bien que, ingenuamente, crelamos.

Para que cayéramos en la cuenta de ello, primero eran los "oficialmente piadosos" (los fariseos), los políticos (los partidarios de Herodes) y los "teólogos" (los escribas, sobre todo los que eran de la capital, Jerusalén) los que no entendlan a Jesús y lo querian matar $(2,1-3,6 ; c f r .3,22-30)$. Despues eran los familiares ( $f f r .3,21)$ y los conciudadanos de Jesús los que no lo entendian ( $c f r$. 6. 1-6a). Tampoco con el pueblo judio, en general, parece Jesús haber tenido más exito (cfr. 4, $11 \mathrm{~s} ; 15,11 \mathrm{ss}$ ). Sin embargo, en el inicio del evangelio parecja

30. Best subraya la lección que los discipulos. fallando, dan a la comunidad: "Si un escritor desea hablar sobre el discipulado empleando hombres como ejemplos, hay dos maneras obvias de aproximarse al tema. $O$ bien puede poner delante una serie de ejemplos de un buen discipulado que deben ser seguidos (asl Daniel 1.6; 2 Macabeos; 4 Macabeos), o bien puede instruir a través de las faltas de sus ejemplos (asf acontece con varios de las historias sobre los patriarcas y David). Marcos escogió el último método" (op. cit., p. 12). Además. como nota Best, ibid., algunos de los miembros de la comunidad de Mc podran haber fallado - por ejemplo, por culpa de las persecuciones- y, entonces. la calda de los discipulos. seguida de su perdón y de su exito misionero. les podía servir de fuente que les diera ánimo". 
que al menos los discípulos sí entendían a Jesús (cfi: 4, 11-12). Pero. como acabamos de ver, Mc nos ha ido preparando para que cayeramos en la cuenta de que lampoco este grupo comprendio realmenie a Jesús.

De lodos modos, ya desde los inicios del evangelio íbamos encontrando un grupo de personas que sl parecian haber comprendido a Jesús y habian estado dispuestas a seguirle hasta la cruz. Me refiero a las mujeres". De hecho, ellas son las únicas que, según Mc. se encuenuran al pie de la ctuz, aunque sólo puedan mirarlo "de lejos" ( $f f r .15,40-41$ ). Esla conducta modélica de las mujeres sería, entonces, como un hilo conductor que acompanaría loda la obra de Mc. De todos modos, antes de sacar una conclusión precipitada, veamos si es así efectivamente.

La primera mujer en aparecer es la suegra de Pedro, de la cual se dice que, cuando Jesús la curb, se puso a servirle (cfr. 1, 29-31). Mc utiliza aquí el verbo diakonéó, "servir", un térraino que Pablo se aplica también a sí mismo para designar una de sus relaciones fundamentales con Cristo (cfr. Rom 1, 1). A Mc este termino le sirve, al colocar este milagto en el denominado "día de Cafarnaum" $(1,21-39)$, para presentar a esia mujer como modelo de lo que significa seguir a Jesús ${ }^{32}$. Pues conviene tener presente que es, precisamente, el senvicio lo que Mc nos presentn como la quintaesencia de la actividad de Jesús, en la tierra: "Pues tampoco el Hijo del hombre ha venido a ser servido, sino a servir y a dar su vida en rescate por todos" $(10,45)$. Por eso el servir debe ser la caracteristica de codo verdadero discípulo y discípula de Jesús: "Jesús llamó a los Doce y les dijo: el que quiera ser el primero, que sea el último de todos y el servidor de todos" (9, 35; cfr. también 10, 43s). En este sentido, la suegra de Pedro aparece como un personaje modélico.

Otra mujer modélica es la mujer que padecía hemorragias desde hacia doce años ( $c f r .5,25-34)$. La ley mosaica le prohibia acercarse a una persona y mucho más tocarla. Pero ella tiene fe, confianza, en Jesús, hasta el punto de creer que el contacto con é, la curará. Por eso, se aureve a romper la ley (una idea muy paulina). Sorprendentemente. Jesús la invila - iy no para condenarla!_ a reconocer en público que ha hecho algo prohibido por la ley. Pues, en el fondo. la mujer ha practicado aquello de que la ley (el sábado) está hecha para el hombre y no el hombre para la ley (cfr. 2. 27). Por eso queda curada y Jesús reconoce que su fe la ha llevado a la salvación (cfr. 5. 34). Por ello, Fander ve en ella, con razón, una figura emblemática. pues ha mostrado la relatividad, la superación.

31. A excepción de las que pertenecen a la familia de Jesús (en el sentido y por las razones que he mencionado antes) y de Herodlas, la esposa de Herodes, y de su hijo (cfr. 6, 19-29).

32. As! interpreta este texto $M$. Fander, en un estudio muy interesante sobre el papel de la mujer, en el evangelio de Me (Die Siellung der Frau im Markusevangelium. Altenberge. '1992, pp. 33s; cfr., pp. 17-32). 
de las normas de pureza cultual. Se irata de algo que Jesús explicará en 7. 1-23. Pero allí. los discípulos aún no lo entenderán. Según Fander.

la mujer que pierde sangre es una figurn de identificación de una determinada comprensión del seguimiento, que obliga al que cree en Jesús a actuar contra las estructuras y dimensiones de la muerte (social) que amenazan la vidas?.

Una tercera mujer, también muy significativa, es la mujer sirofenicia, una pagana. por tanto (cfr. 7, 24-30). Su hija está enferma. Pero ella, aun siendo pagana, tiene fe en Jesús. Confla que $\mathrm{El}$ curará a su hija. Pero Jesús no puede acceder, sin más, a su petición. pues se sabe enviado ante todo a las ovejas de Israel que estaban sin pastor (cfr. 6, 34). Por eso, de entrada, rechaza su petición, dado que el destinatario primario de su misión, de acuerdo con lo prometido por Dios, en el Anliguo Teslamento, es el pueblo de Israel (cfr. 5, 27: "deja primero que se sacien los hijos, pues no está bien tomar el pan de los hijos y echárselo a los perrillos"). Pero la mujer no se deja perturbar, no pierde su fe en Jesús, por este rechazo aparente. Al contrario. Insiste en su petición. Más aún. muestra a Jesús por qué se pueden superar los límites de Israel: "Es cierto. Señor, pero también los perrillos, debajo de la mesa. comen las migajas de los niños" $(5,28)$. Y Jesús se deja enseñar por ella, juna mujer y, además, paga$n a !^{\text {24 }}$. Se trata de un texto importante, porque el autor está pentsando en la instrucción a su comunidad, a la que ayuda a entender cómo se ha pasado de una predicación destinada, inicialmente a Israel, a una predicación que se ha extendido al mundo pagano. Jesús, por otro lado, reconoce el valor de esta fe, cuando le dice a la mujer. "Por haber hablado asf, vete, que el demon-o ha salido de tu hija" $(5,29)$. Nótese, además, como indica Fander", que la mujer sirofenicia es la primera persona que aplica a Jesús el tílulo cristológico de "Señor" (Kyrios).

Una cuarta mujer modélica la encontramos en la viuda pobre, que hecha dos monedas, en el cofre de las ofrendas del Templo (cfr. 12, 4/s). Tambien ella es alabada por Jesús. Y es una alabanza notable, pues Jesús dice de ella: "Les aseguro que esa viuda pobre ha echado en el cofre más que lodos los demás. Pues todos han echado de lo que les sobraba; ella, en cambio,' ha echado de lo que necesitaba, todo lo que tenía para vivir" $(12,435)$.

Por último, Mc presenta la mujer que se gasta el sueldo normal de un año (más de 300 denarios) en un perfume, que emplea para ungir su cabeza (cfr. 13,

33. Op. cir., p. 54: sobre toda la escena. Vease lo que dice en pp. 35-62, sobre lodo pp. 52-62.

34. Fander. op. cit.. p. 83, nols que, a nivel de la redacción. sólo aqui aparece Jesús cambiando su parecer.

35. Op. cit.. p. 81. Precisamente por esta fe (ibfdem p. 84). Fander la ve como prototipo del pagano creyente y símbolo de la lglesia, que proviene del paganismo. 
3-5). Los varones que esún en la mesa con Jesús la critican, por considerar su acción como un despilfarro. Pero Jesús la defiende y dice que se recordará su acción en cualquier parte del mundo, donde se predique el evangelio (cfr. 14, 69). Y ello es así porque su acción muestra que es la primera persona que ha sido capaz de comprender que la muerte de Jesús es de valor infinito, jno tiene precio! Y lo más sorprendente es que la primera en descubrir el valor de la muerte de Jesús ("ha ungido su cuerpo para la sepultura": v. 8) ;sea una mujer!

En este conlexto ya no tiene, entonces, por qué sorprendernos, como decía antes, que al pie de la cruz se encuentren, de hecho, sólo mujeres. Son unas mujeres que han seguido a Jesús hasta Jenusalén y le habían servido desde Galilea (cfr. 15,40-41). Serán, precisamente, estas mujeres las que se convertirán en testigos de la sepultura de Jesús (cfr. 15, 47) y las que el domingo por la mañana se dirigirán al sepulcro del Maestuo $(c f r .16,1)$. Por eso, serán ellas las prineras que recibirán la revelación divina de que Dios ha resucitado a Jesús (cfr. 16, 5-7) ${ }^{36}$. Hasta ahora, sólo hablan visto (theóréo) el lugar en el cual habia sido depositado su cadáver (cfr. 15, 40a.47b); ahora, ven (hor $(6)$ ) al enviado celestial (el joven vestido de blanco: v. 4), como luego verán (hord6), ellas y los disclpulos, al resucitado, en Galilea".

Según T. Söding", el hecho de que Mc indique que las mujeres "ven" al encificado (cfr. 15, 41), las relaciona con el "ver" del centurión, al pie de la cruz (cfr. 15, 39). $Y$ añade:

Esto es, en mi opinión, una indicación de que Marcos ha querido ver una cosa como complementaria de la otra. Más exactamente: si en la concepción marcana es el camino global de Jesús lo que fundamenta la confesión del centurión y el único lugar desde el que esta confesión de fe cristológica

36. El hecho de que las mujeres sean las primeras en recibir el mensaje pescual es una manera de comunicar, narrativarnente, que Dios es. por esencia, el "Dios de la gracia" ( $c f r$. Rom 11, 25-32: cfr. X. Alegre. "Universalisme i elecció en la perspectiva del Déu de la Gràcia", Associació Brblica de Catalunya, Burllerr 13-14 (1980), Pp. 412). Y por ello, con la muerte de Jesús en la cruz, he roto los moldes y los "ćllculos religiosos" de los seres humanos, ya que se manifiesta, no en la gloria, sino en la cruz: no sólo a los judlos, sino también a los paganos; no a los discípulos (hombres), sino también, y de modo perticular, a unas mujeres...

37. Como indica W. Grimm, Markus - Ein Arbeissbuch aum älsesten Evangelium. Philologische. historische und theologische Klörungen, Stutlgart, 1995. pp. 9 y 122. el uso de un vocabulario distinto para el motivo "ver" es seílal de que Mc distingue entre dos formas de ver. hasta ahora las mujeres hablan visto (theóréb) lo que se puede ver empiricamenle; ahora, pueden "ver" (horód) lo que Dios revela.

38. Glaube bei Markus. Glaube an das Evangelium, Gebessglaube und Wunderglaube im Kontert der markinischen Basileiatheologie und Christologie, Suttgant, 1985. pp. 2745. Sobre el significado del seguimiento y del servicio en las mujeres. cfr. ibid., pp. 143 146. Hay una inclusión entre este servicio y el que realiza la suegra de Pedro, en 1, 3 I. 
puede obtener su verdad, en la misma línea el evangelista ha visto en las mujeres (galileas) personas que han hecho este camino de Jesús hasta el final, en una actitud de seguimiento dispuesto al servicio.

Al constatar este hecho parece. consecuentemente. que al menos hay un grupo. las mujeres, con el que la comunidad de Mc se puede identificar de forma positiva. en el sentido de que la comunidad se hallaris, despues de pascua. a un nivel de conocimiento tan profundo como el que hasta este momento han manifestado las mujeres.

Pienso que es por este motivo que ahora Mc, con un procedimiento dramático muy propio de el. quiere mostrar que ni siquiera las mujeres - jincluso después del anuncio pascual! - fueron capaces de comprender bien el mensaje de Jesús ${ }^{30}$. Porque el resucitado, como recuerda el anuncio angelico de la resureceión. sigue siendo, después de pascua. el "Nazareno" y el "Crucificado" (efr. 16,6). Fijémonos en que la eleceión de estos dos útulos, unidos al mensaje de la resurrección de Jesús, no es casual, en Mc. Pues, no se puede comprender lo que significa que Dios ha resucitado a Jesús al margen de la vida de Jesús de Nazaret, una vida que lo llev6 a la cruz (y llevará fácilmente a ella a todo el que quiera seguirlo: cfr. B, 34ss). Y el mensaje de la cruz sigue siendo difícil de comprender, contracultural (efr. ICor 1, 18-25).

Esto explicaria que también las mujeres, al final del evangelio de $\mathrm{Mc}$, aparecieran como incapaces de comprender el mensaje de Jesús. Pues. de hecho, su huida del sepulcro (16, 8b) recordara al lector la huido de los discípulos, que Mc ha narrado poco antes (cfr. 14, 50: tambien 14, 51s) ${ }^{\text {so }}$. Y su silencio, al final

39. En esta línea de interpretación. L. Schortoff ("Maria Magdalena und die Frauen am Grabe Jesu". Evangelische Theologie 42 (1982). p. 29) califica el silencio de las mujeres como una seria incomprensión, por pare de estas discipulas de Jesús. Un análisis minucioso de la pericopa 16, 1-8, intentando dilucidar qué es de la tradición y que de la redacción. la encontraros en Fander, op. cir.. pp. 147-176.

40. Es lo que seriala T. E. Boomershine. "Mark 16, B and the Apostolic Commission". Joumal of Biblical Literalure 100 (1981). p. 229. cfr. p. 236. destacando su contexto muy negativo. dado que la huida de los discípulos era presentada como algo muy escandaloso y en relación con la vergúenza de la huida del joven que corre desnudo (algo en principio humillante). En el contexto del anuncio gozoso de la resurrección. el silencio de las mujeres serfa una inversión de las expectativas. que resultaria chocante. Por ello. critica (ibld, pp. 228.230) la interpretación positiva que hace R. H. Lightfoot. The Gospel Message of St. Mark, London, 1962, p. 97, en el sentido de que el temor y el silencio serian la reacción reverente de las mujeres ante la revelación divina. Según Boomershine, en cambio, "el carácter del final de Mc sugerira que sus oyentes estaban enfrentados a una situación en la que la proclamaeión del evangelio comportaba unos riesgos extremos y estaba asociada con el miedo. El final. sin embargo, indiea que para Marcos la hulda en el silencio era el peligro supremo a la vez que la ironia fundemental" (op. cit., p. 238). 
del evangelio (16, 8b), mostraria que no han comprendido el significado de la resurrección del crucificado y la tarea que Dios les ha confiado de ser testimonio. para los discipulos de Jesús. del itinerario que lleva a la experiencia pascual. Un itinerario que queda simbolizado teológicamente en Me con la palabra "Galilea".

Esta incomprensión final ya había sido preparada de forma narrativa, al inicio del relato de la tumba abierta, por el hecho de que en 16. 1.4 se presenta a las mujeres yendo a la lumba para ungir el cadáver de Jesús. Se traca de un motivo posiblemente redaccional", que resulta un poco absurdo y que revelo, al lector de Mc, que las mujeres no han comprendido tampoco. en el londo, el mensaje de Jesús ${ }^{42}$. Pues implica que buscaban a Jesús entre los muertos y, por tanlo, que babían olvidado, o por lo menos no habfan creldo su palabra, que había anunciado en diversas ocasiones su resurrección al tercer dla (cfr. 8, 31; 9. 31: 10,34$)^{43}$. Como tampoco habian tomado en serio la palabra de Jesús, en la cena de despedida, de que después de su muerte debian ir a Galilea pues Jesús les precedería allá y allá podian verle (cfr. 14, 28). Y ello al margen de lo que Jesús había dicho, a proposito de la mujer que le habfa ungido, en casa de Simón el leproso: ella ya había ungido su cuerpo para la sepultura (cfr. 14, 3ss). En la misma línee de preparar narrativamente el fracaso de las mujeres, podemos ver el hecho de que Mc ridiculiza un paco su intento, en 16,3 , cuando señala que tan sólo por el camino (iy no se detienen por ello!) caen en la cuenta de que no serlan capaces de quitar la piedra, que sellaba el sepulcro"

¿Cuál es, pues, el significado del silencio sorprendente de las mujeres, al final del evangelio de Mc? Pienso que, con lo que hemos visto, la respuesta resulta clara. Mc quiere mostrar, con todos los medios a su disposición, hasta que punto resulta diffcil de comprender, de manera adecuada, quién fue y es realmente Jesús de Nazaret. el crucificado, a quien Dios resucitó, dándole la razón frente a sus adversarios. El silencio de las mujeres, al final del evangelio. abunda en la idea que dejaban ya entrever los otros silencios, que hablamos encontrado en Mc. El sileneio de las mujeres servirfa, entonces, de recordatorio perenne de la dificulad que comporta el mensaje de la cruz, lambién despues de la resurrección de Jesús. Con ello. Mc quila al oyente-lector del evangelio la

41. Por ejemplo, Schmill, op. cir. Pp. 533 y 558, considera que los vv. 3 y 4 son de la redacción de Mc.

42. Como subraya N. Perrin. The Resurrection Norratives. A New Approach, London. 1977. p. 32, "al igual que los discípulos, las mujeres tambien le fallan a su maestro [...]. En el Evangelio de Marcos el fallo de los discipulos es loul".

43. AsI. Iersel, Markuskommensar, p. 248.

44. Este rasgo, si fuera de la tradición. como piensan algunos autores, habría servido inicialmente para poner de maniliesto de forma apologética, que las mujeres no podian ser responsables del robo del cadaver, en la turaba. 
última posibilidad que le quedaba para identificarse con unos personajes concretos del evangelio. De hecho, podrían pensar que ellos, despues de pascua, gozarían de la misma comprensión profunda de Jesús de la que las mujeres habían dado muestra. a lo largo del evangelio. Por ello, Mc quiere sacudir ahora, por última vez, las concepciones triunfalistas de sus cristianos y cristianas y la falsa seguridad de todas las personas que corren siempre el peligro de olvidar la paradoja radical y la novedad siempre escandalosa de la revelación cristianats.

Esta interpretación viene confurmada por la dificultad objetiva que comporta cualquier intento por expresar, en lenguaje humano, lo que fueron las experiencias pascuales -y ello, en una época, la de la comunidad de Mc, en la cual las experiencias pascuales fundantes de la comunidad cristiana son algo del pasado (Pablo fue el último de estos testigos privilegiados: ofr. ICor 15, 8-11), algo que ya no experimentan ahora los destinatarios del evangelio. Es to que opina Sommer cuando, después de concluir que Me quiso terminar su obra con el silencio de las mujeres, comenta"s:

Ya se indico antes, que no se puede describir el mismo milagro de pascua, sino sólo sus "huellas", como la piedra que ha sido quitada o la tumba vacía. La posibilidad de relatar lo sucedido choca con límites. Lo más importante ya no puede ser comunicado, sino que hay que captarlo en la fe. Lo que se puede decir sobre Jesús, se termina con el mensaje de la resurrección. Tampoco los relatos sobre las apariciones pueden cambiar nada en este hecho; tan sólo pueden aludir a lo que fue el misterio pascual. También después de la resurrección. Jesús es caracterizado como "el Nazareno, el Crucificado" (v. 6). Con ello su historia sigue siendo importante. pues en ella se hace visible su identidad. Por esio no hny que comprender la ausencia de relalos de apariciones como una merma; el evangelio puede terminar con 16, B. Y, al terminar as! muestra dos cosas: 1) la dureza de mollera de todo ser humano en lo que se refiere a la fe [el autor, ibld. lo denomina Begriffsturzigkeir]; 2) y que lo que se ha hecho patente en la historia de Jesús no puede ser realizado por el ser humano sin más, sino que es un don (de Dios).

\subsection{La estructura del evangelio de Mc}

Lo que acabamos de ver vendría confirmado por el análisis de la estructura que Mc dio a su obra y que aquí no puedo desarrollar". Sólo quiero destacar un

45. "Su desconcierto en la maĩana de pascua [se refiere al de las mujeres en $16.8 \mathrm{~b}$ ] pone fin a la evocación dmárica, a lo largo de codo el segundo evangelio, de la imporencia humara para penetrar el misterio revelado de Jesuctisto" (Delorme, Resurrección. p. I 10).

46. Die Passionsgeschichre des Morkusevangeliums. Túbingen. 1993, p. 235: ff. pp. 234-238. Sobre la gratuidad de la fe y su relación con la visión. asl como la interrelación entre la fe y la historia, vease lo que este autor dice en pp. 239-266.

47. Lo hice més ampliamente en mi artículo: "Marcos o la corrección de una ideologla triunfalista. Paulas para le lectura de un evangelio beligerante y comprometido", Revista 
aspecto que me parece esencial. Me refiero al hecho de que la estructura del evangelio viene configurada por la cruz de Jesús y por el escándalo que su vida provaca.

El conflicto de Jesús con las fuerzas religiosas y polfticas de su tiempo es para Mc la parte visible del iceberg que, simbolizado por el demonio (cfr. 1, 12s y los exoreismos), intenta aniquilar a Jesús, desde los inicios de su actuación (efr. 3. 6). Mc expone toda la vida de Jesús como un drama, de magnitud escalológica4, que culminará en la pasión y en la muerte del Justo en la cruz. La cruz, entonces, manifestará, por un lado, de qué son capaces los enemigos de Dios y del ser humano, con tal de acallar la voz del Hijo del amo de la viña (el Hijo de Dios), que les reclama los Irutos de la cosecha del Padre (cfr. 12, 1-12). Por otro lado, comportara también, paradojicamente, el triunfo de Jesús (cfr. 15. $39 ; 16,6 s)$.

Mc quiere que a la luz del conflicto histórico, que provocó el modo como Jesús hacía presente el reino de Dios en el mundo, se descubra hasta qué punto "el conflicto" es inherente a tods opeión de vida cristiana, que se tome en serio el seguimiento de Jesús de Nazaret. Por esto anuncia claramente a la comunidad que sert perseguida (cfr. 13, 9-13) y que necesita la oración. si no quiere tropezar, en medio de las dificultades que le esperan (cfr. 14, 38). En todo caso, está necesitada también de una vigilancia atenta ( $c f r .13,5.9 .23 .33 .35 .37)$.

Lotinoamericana de Teologia 2 (1985). pp. 234ss. Fundamentalmente, me apoyaba en la estructura que propuso E. Schweizer, "Die theologische Leistung des Markus", Evangelische Theologie 24 (1964), pp. 342-355 (la condensacion de este arificulo apareció con el túlo "La aportación teológica de Mareos", en Selecciones de Teolo. gía 9 (1970), pp. 50-61), y en la elaboración ulterior de esta estructura, que hizo I. de la Potterie ("De compositione Evangelii Marei", Verbum Domini 44 (1966), pp. 135. 141; en este articulo se pueden ver tambien las ventajas e inconvenientes de otros modos posibles de estructurar el evangelio de $\mathrm{Mc}$ ). Sobre la estnuctura de Mc puede verse tambien Delorme, Evangelio, p. 33, y D. A. Koch, "Inhaltliche Gliedenung und geographischer Aufriss im Markusevangelium". New Tesioment Srudies 29 (1983). pp. 145-166. Este último aunor distribuye en tres grupos las estructuras de Mc, que proponen los evangelislas, según que el principio estructurador sea geográfico, temśtico, o un compromiso entre ambos. Para una estructura en la cual. aun reconociendo que la teología crucis estr en el centro de la perspectiva de Mc, se destacan más, sin embargo, otros aspectos como la resurrección de Jesús o su ministerio terrenal (que son esenciales tambien en mi interpretsción), ofr. Fusco, op. cit., pp. 114-132. lersel, op. cil., pp. 66-74, propone ung estructura concéntrica (jalgo que, por otro lado, encontrmos en muches pericopas de Mc!). que estarfa centrada en torno al fragmento 8, 27 10,45 y enmircado por las dos curaciones de eiegos), un texto estructurado en tomo a los tres anuncios de la muerte y resurreceión de Jesús $(8,31 ; 9,31 ; 10,32.34)$.

48. Cfr. Minette de Tillesse, op. cir., pp. IIOS. 


\section{La revelactón de Jesús como Hijo de Dios en la cruz}

Después de lo que acabamos de ver, ya no nos sorprendera que el titulo por excelencia que Jesús recibe en Mc -el título de "Hijo de Dios" (cfr. 1. 1.11: 9. 7; 15. 39; cfr. también 5,$7 ; 3,11)^{40}$ - se encuentre tan sólo una vez, en boca de un hombre -iy es un pagano! ${ }^{30}$. Y que ello ocurra, precisamente. al pie de la cruz. En este contexto es obvio que ahora ya no hace falta ninguna "orden de silencio" o nada parecido que tenga que poner sordina a este vitulo. Pues el centurión pagano, al que Mc presenta como un convertidos'. 10 confiese al pie de la cruz. Y lo hace viendo cómo Jesús ha expirado, lo cual nos hace tomar conciencia de que Mc presenta la muerte de Jesús con toda su dureza, pues muere gritando y rezendo: "Dios mio, Dios mfo, ipor qué me has abandonado?" $(15,34$, una cita del Sal 22,2$)^{32}$. Es en este contexto, carente de cualquier signo glorioso, que el centurión proclama: "Verdaderamente este hombre era Hijo de Dios" $(15,39)$. Es evidente que al pie de la cruz se puede confesar con toda libertad la filiación divina de Jesús, pues en este lugar no hay peligro de equívocos triunfalistas, si se confiesa que Jesús es el Meslas, el Hijo de Dios ${ }^{33}$.

A mismo tiempo, Mc tiene interés en mostrar, con el detalle de que al morir Jesús en la cruz el velo del Templo se rasga en dos ( $f r$. 15. 38), que es en la cruz donde aparece el final de la antigua alianza. Y es en la cruz donde los paganos tienen acceso a la fe. De la cruz parte la misión cristiana a los paganos".

\section{Conclusión}

Después de lo que hemos visto aparece con claridad que la cruz se convierte en el cllmax del evangelio de $\mathrm{Mc}^{35}$. Y se convierte en la piedra de toque que

49. Cfr. Gnilka, op. cit. I, pp.70-73; B. Maggioni. El relaro de Marcos. Una iniciación al misterio cristiano, Madrid, 1981, pp. 15-17.

50. No es ninguna casualidad que sea precisamente un pagano el que confiese el que Jesús es el Hijo de Dios, pues al ser un pagano, muestra con claridad que el ser humano no liene "derechos especiales" delante de Dios. por el hecho de ser miembro del pueblo escogido por Dios o por haber recibido la revelación biblica.

51. Ast lo interpreta Kingsbury. Chrisłology. p. 131: cfr. lambién Dormeyer, Passion Jesu, p. 213; Schneider, Passion Jesu, p. 128.

52. Asi lo indica con razón Steichele, op. cit., p. 295; cfr., pp. 271-273.

53. Cfr. Minelle de Tillesse, op. cil., pp. 340 y 358. Como observa Best, op. cir. pp. 13s: "Se necesita fe. Pero una le que no está relacionada con la eruz sólo extravía. La naturaleza del discipulado aparece sólo a la luz de la cruz y no a la luz de los actos poderosos de Jesus".

54. Cfr. Grilka, op. cit. II, pp. 379s.

55. Asf lo ve Perrin, op. cir., p. 19. Por tanto, no es la resurrección el climax del evangelio, aunque es ciento que tsta tiene, obviamente, una importancia fundamental, en Mc (cfr. Steichele, op. cif., pp. 305s). Tampoco se encuentra el climax en la parus[a: "El contenido del evangelio se define mueho mas en términos de la enuz que en los de la 
permite al creyente examinar si verdaderamente se encuentra en el seguimiento de Jesús de Nazaret El silencio de las mujeres en 16,8 no hace sino subrayar este hecho.

Ello explica por que Mc no quiere concluir su obra con el relato de las apariciones pascuales, pues éstas podrían quitar fuerza a la dureza interpeladora del evangelio. El silencio final de las mujeres le sirve a Mc para recordar a su comunidad que, incluso despues de pascua, la sombra de la cruz sigue planeando sobre la comunidad cristiana. Y que ésta sólo podrá revivir la experiencia pascual que la llevó a la fe y a encontrar a Jesús, si se coloca en la sinación adecuada para poder seguir a Jesús, el crucificado. Se trata de un seguimiento que comporta, obviamente, un estilo de vida que molestará siempre a los poderes egoístas de este mundo.

Como este seguimiento del crucificado resulta diffcil, por eso Mc tiene inteits en dejar abierta, al final de su obra, la posibilidad del fracaso, el peligro que tiene la comunidad de acabar negando a Jesús, aunque sea por miedo a la persecución (a ésta aludia Mc claramente en 13,9.13). Así interpela a su comunidad.

Por eso, Tolbert saca la conclusión siguiente, hacia el final de su obra, aludiendo a lo que Mc dice, en la parábola del sembrador (cfr. Mc 4,3-9.14-20)"s?:

El problema que plantea el epnlogo en términos fuertemente relóricos, a vavés de las expectativas incumplidas que habian suscitado las mujeres mencionadas, es el siguiente: si estas seguidoras no fueron ni contaron, iquien lo hizo? Al final, el evangelio de Marcos deja conscientemente a cada lector u oyente ante la cuestión urgente e inquietante: ¿Qué tipo de tierra soy yo? ilré yo y contaré? Efectivamente, la respuesta de cada uno a la semilla sembrada por el evangelio de Marcos revela en el corazón de cada creyente, como lo hizo antaño la predicación de Jesús, la presencia de la tierra de Dios o de la de Satán.

Al empezar el articulo afirmaba que el silencio de las mujeres, en Mc 16, 8, era un "silencio elocuente". Ahora podemos entender por qué es asl, efectivamente. Pues espero haber mostrado cómo este silencio se puede convertir para nosotros en clave de lectura de la obra del evangelista. Y en recordatorio perenne de lo que significan la vida y la muerte de Jesús de Nazaret para nosotros hoy". ¡Según Mc, este aspecto es esencial para todo creyente!

parusla; y la capacided para ser un cristiano aparece mucho más en clave de presencia de Crisıo que en le del funuro de la esperanza del final" (Best, op. cir., p. II).

S6. Asl, Fander, op. cit., p. 383.

57. Op. cir., pp. $298 \mathrm{~s}$.

58. Como nota Fusco (op. cis., p. 121): "No basta con afirmar que toda la vida terrena de Jesús es leída a la luz de la pascua: sucede que hay que antadir, con la misma insistencia, que también la pascue, a su vez, es interpretada a traves de la narración que la 
Ahora podemos entender también por que. en Mc, toda la vida, muerte y resurrección de Jesús de Nazaret queda enmarcada por la vocación de Pedro y de los discípulos ( $c f r .1,16-20$ y 16, 7). Ello es así porque, para Mc, la experiencia pascual que se encuentra en los inicios de la comunidad cristiana fue, en lo esencial, una experiencia de vocación $n^{30}$. Se trata, en concteto, de una vocación que llama a seguir a Jesús en el camino que lo llevo a la cruz, donde él entreg6 su vida, "en rescate por todos" $(10,45)$. y a dar testimonio con la propia vida de lo que fue la vida de Jesús. Esta vocación implica, al mismo tiempo, una conversión radical y continuada.

Los rasgos propios de la experiencia pascual, que encontramos ya en Pablo y en los testimonios más antiguos de la resurrección de Jesús (conversión, vocación-misión y lestimonio), han sido mantenidos y subrayados por $\mathrm{Mc}$, al ẳadir al relato de la lumba abierna el $v$. 7 y al desarrollar nanativamente la vida de Jesús de Nazaret como clave hemenéutica fundamental y como camino iniciático insustituible de toda experiencia de la resurrección de Jesús ${ }^{\infty}$.

A medida que pesó el tiempo, las comunidades cristianas, más preocupadas por otros problemas dogmáticos o apologéticos, fueron poniendo otros acentos. en sus evangelios, por lo que la preocupación teológica central de Mc pasó a un

precede". Con todo, yo subrayaria aún más que Fusco que Mc, por fidelidad a Jesús de Nazaret, mantuvo viva para la comunidad cristiana la "memoria peligrosa" (en formulación de Metz), en eierto sentido, "subversiva", de Jesús de Nazaret. Solo así piensa Mc que se puede mantener, sin que resulte ambigua, la revelación de la gloria del resucilado. gloria que ya se transparentaba en la transfiguración (cfr. 9. 2ss), pero que también allí quedaba claramente enmarcada por la revelación de la pasión y de la cruz (cfr. su contexto inmediato: 8, 31 ss y 9. 9: cfr. Achtemeier, op. cit., pp. 101s). Llama la atención que la transfiguración de Jesús y la aparición de Elías y de Moisés provocan también la incomprensión de Pedro y de los discípulos (cfr. 9, 5-6a), incomprensión que es explicada de forme literaria de una manera semejante a la que encontramos en 16, 8b: ékphoboi gàr egénonio $(9,6 \mathrm{~b})$.

59. Según los texios bßlicos. éste es uno de los aspectos fundamentales de la experiencia pascual: cfr. B. Klappert (ed.). Diskussion un Kreuz und Aufersiehung. Wuppertal, 41971, pp. 29s. Según este autor, "esta conexión entre el apostolado y las apariciones del Resucitado, que se acaba de mosirar para Pablo, es también esencial para los evangelios: las apariciones del resucitado son. a la vez, la lamada a la misión" (op. cir., p. 30). En cuanto al problema de si es repetible o no hoy la experiencia pascual, cfr. G. Lohfink, "La muerte no es la última palabra", en G. Lohfink; R. Schnackenburg; A. Vögtle y W. Pannenberg, Pascua y el hombre nuevo, Santander, 1983, pp. 11-28.

60. Esta es la conclusión que saca J. Emst, después de señalar la identidad entre el Jesús resucitado y Jesús de Nazarec, en Mc: "El seguimiento aetual de Jesús por parte de la comunidad desde la ojeada retrospectiva al discipulado en Galilea es, para Mc, la forma válida de las apariciones. El final del evangelio queda abiento por razones teológicas" (Das Evangelium nach Markus, Regensburg. 1981, p. 498). 
segundo plano". Por esta razón, en el siglo Il. se llegó incluso a "completar" la obra de Mc añadiéndole diversos finales". Mc, en cambio, al intentar la traduc-

61. De todos modos. incluso MI, que manifiesta, sin duda, un interés apologético cn sus rclatos paseuales sobre la tumba abierla, ha manicnido bicn claro - a pesar de que él sí tiene relatos de apariciones pascuales del resucitido- uno de los molivos centrales de Mc: In imporlancia de la vida de Jesús de Nazaret y de la enscñanza que realizó durante su vida públici, dado que ambas siguen siendo válidas, después de pascua. Esto es to que aparece en la aparición que narra del resucitado a los once, en la montaña de Galilca (efr. MI 28, 16-20). En cstc texto, la monlaña de Galilca (cfr. 28. 16). además de ser un lugar lípieamente tcuf́́nico, quicre ser una alusión clara al primer discurso de Jesús. el denominado "scrmón de la montaña" (Mi 5-7). En csia aparieión, en la que MI recuerda la inicialiva gratuila de Jesús, el cxaltado a la derecha de Dios, que sc aparece a sus discipulos (cfr. MI 28. 17), Mi scriala en qué ha de consistir la actividad de los discípulos de Jesús despues de pascuil: han de "converlir en discípulos (de Jesús)" a "Iodos los puchlos" (también a los paganos, por lanto). Y lo han de hacer, "bautizándolos" y "cnschíndolos a guardar" todn lo que El (Jesús de Nazarct) les habia cnseñado (efr. 28, 18-20). Por cso, M1, a cjemplo de Mc, explica en su cvangelio, aún más ampliamente que Mc. la vida, las palabras y lias obras de Jesús de Nazaret (cfr. J. Zumstcin. La condition du croyant dans l'Évangile selon Matthieu, Frciburg-Göttingen, 1977. pp. 86-106). Notcmos lambięn, a propósilo de la manera como Ml cuenta las apariciones pascuales, que tambićn él. a scmejanza de lo que ocurria en las tradiciones más antiguas sobre las apariciones del resucitado, no se deliene en expliear en qué ennsistió la "visión" (efr. v. 17a: idb́ntes) que los discípulos tuvieron del resucitado. Relata más hien la misión y vocacion de éstos (vv. 18-19a) y la promesa del resuciladi de que c'stará eon ellos -jen ruturo! - hasla el fin del mundn (v. 2(h). Y con esta promesa que hace inclusión con Mi 1. 22-23 (el Dios-enn-mosotros), Mi coneluye su evangelio. De todos modios. en MI encontramos ya más desarrollado el esfuerzo de los primeros cristianos por expliejtar namativamente el significado de las apariciones pascuales. Se trataba de un esfuerzo nada [ácil, pues la resurrección de Jesús nos confronta con una "barrera de lenguaje" de primer grado - ies un acontecimiento escatológico!- como señala con razón A. Vögle, op. cif., p. 12, apoyándose en R. Schnackenburg "Biblische Sprachbartieren". Bihel und Lehen 14 (1973), pp. 223-231. (Schnsckenburg reflexiona ampliamente en su artíeulo sobre los problemas que la revelación divina plantea al lenguaje humano.)

62. Quizás to hicieron impulsados por preocupaciones "tradicionalistas" que. como ocurre a menudo, suelen ser las menos uradicionales de Iodas. si se piensa en la Tradición (con mayúscula). En todo caso. cuando "completaron" la obra de Mc, no cayeron en la cuenla de que el linal, aparentemente inncabado y, en todo caso, desoncertanle. de la obra era, precisamente, une clave de lectura de lodo el evangelio. Y era una clave que el mismo evangelista habia pretendido. Como indica Best, a propósitn del final original de Mc: "Sugerir que 'termina' da, quizás, la idea equivocada. La resurreceión - no se narra ninguna aparición- es presentada de tal modo que es también el comienzo; desde ahí se abre une vida nueva; cuando se lee el libro y se vive su mensaje, el Jesís resucitado se hace presente" (op. cir., p. 11). Según Hug, op. cit., p. 223. los vv. 9-20 del epitulo 16 representan una relectura de origen pastoral. Pero 
ción narrativa del kerigma primitivo y al actualizarlo para su comunidad, se preocupo de mantener muy vivo aquel aspecto que Pablo consider siempre como el esencial: el escándalo de la cruz (cfr. 1Co 1,22-25).

Al concluir la lectura de Mc, por tanto, el autor nos pregunta: "creyente, ¿qué dices de ti mismo?" ${ }^{3}$. ¿Con qué personaje del evangelio te identificas? ¿En que estadio del seguimiento de Jesús te encuentras? ¿Es verdad que sigues al crucificado, a quien Dios resucito, porque era el Justo?

La respuesta adecuada a lodas estas preguntas no la tenemos asegurada, si no es en la misericordia de Dios.

ailade: "la perspectiva optimista de Mc con sus signos prometidos a los creyentes, sin mencionar ningún comectivo, no se deja armonizar con el camino del disclpulos que Mc quiere inculcar a sus lectores ( $f$ r. $4.17 s ; 8,27-35 ; 9,30-37 ; 10,32-34$, eic.), un camino de la cruz como lo ha sido el del Maesuro".

63. Cfr. J. Radermakers, La bonne nouvelle de Jesus selon saint Marc, Bruselas, 1974. vol. I. p. 436. Como seîala U. Luz, la narración marcana implica un acontecirniento. en el mismo oyente o lector. "En su trascurso se transforma su propia precomprensión, el mismo es cuestionado en su comprensión de [...] la gloria de Cristo. El evangelio de Marcos les saca el tren de la vía [verfremdet] a sus oyentes" ("Toologfa crucis als Mille der Theologie im Neuen Testament", Evangelische Theologie 34 (1974) p. 136). 